\title{
PERFIL HEMATOLÓGICO E BIOQUÍMICO DE OVINOS SUPLEMENTADOS COM SALINOMICINA SUBMETIDOS À ACIDOSE LÁCTICA RUMINAL
}

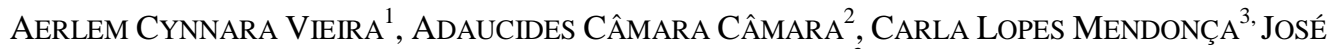 \\ Augusto BASTOS AFONSO ${ }^{3}$ \\ ${ }^{1}$ Doutora em Medicina Veterinária pela Universidae Federal Rural de Pernambuco, Recife, PE, Brasil - acynnara@ gmail.com \\ ${ }^{2}$ Mestre em Ciência Animal pela Universidade Federal do Semi-Árido, Mossoró, RN, Brasil \\ ${ }^{3}$ Médicos Veterinários Doutores da Clínica de Bovinos, Campus Garanhuns da Universidade Federal Rural de Pernambuco, \\ Garanhuns, PE, Brasil
}

Utilizaram-se 12 ovinos distribuídos nos grupos controle (GC) e no salinomicina (GS) com objetivo de estudar alterações clínicas, hematológicas e bioquímicas nos ovinos suplementados com o ionóforo e avaliar seu efeito na prevenção da acidose ruminal experimental. Induziu-se acidose ruminal com sacarose e as variáveis foram analisadas $4 \mathrm{~h}, 8 \mathrm{~h}, 12 \mathrm{~h}, 16 \mathrm{~h}, 24 \mathrm{~h}, 32 \mathrm{~h}$ e $48 \mathrm{~h}$ pós-indução (PI). Determinaram-se as enzimas AST, GGT, FA, CK, as proteínas totais séricas (PT), albumina, ureia, creatinina, hemograma, proteína plasmática total (PPT), fibrinogênio (FP), glicose e L-lactato. Manifestações clínicas de acidose láctica ruminal e os menores valores de $\mathrm{pH}$ foram observadas $8 \mathrm{~h}$ PI, com $(\mathrm{P}<0,05)$ no GS comparado ao momento $0 \mathrm{~h}$. Os neutrófilos apresentaram maiores contagens $(\mathrm{P}<0,05)$ no GC $4 \mathrm{~h}$ PI comparado ao GS. O FP alcançou maiores valores $(\mathrm{P}<0,05)$ no $\mathrm{GC} \quad 48 \mathrm{~h}$ PI comparado ao GS. A uréia diminuiu $(\mathrm{P}<0,05)$ em ambos os grupos $12 \mathrm{~h}$ PI. A glicose aumentou $(\mathrm{P}<0,05)$ no $\mathrm{GC}$ comparado ao momento 0 h. Houve queda $(\mathrm{P}<0,05)$ do $\mathrm{pH}$ urinário no momento $12 \mathrm{~h}$ até $48 \mathrm{~h} \mathrm{PI}$, em relação ao momento 0h no GC, enquanto no GS apenas os momentos $12 \mathrm{~h}$ e $16 \mathrm{~h}$ PI apresentaram diminuição $(\mathrm{P}<0,05)$. A salinomicina não preveniu a acidose; no entanto, favoreceu o restabelecimento dos animais tratados.

PALAVRAS-CHAVE: Bioquímica clínica; distúrbio fermentativo; ionóforos; pequenos ruminantes.

\section{HEMATOLOGICAL AND BIOCHEMICAL PROFILE OF SHEEP SUPPLEMENTED WITH SALINOMYCIN SUBMITTED TO EXPERIMENTAL LACTIC RUMINAL ACIDOSIS}

\section{ABSTRACT}

Twelve sheep were distributed into two groups, control (CG) and salinomycin (SG), to study clinical, hematological and biochemical alterations in sheep supplemented with the ionophore and to evaluate its effect in preventing experimental lactic ruminal acidosis which was induced with sucrose. Variables were analyzed at intervals of $4 \mathrm{~h}, 8 \mathrm{~h}, 12 \mathrm{~h}, 16 \mathrm{~h}, 24 \mathrm{~h}, 32 \mathrm{~h}$ and $48 \mathrm{~h}$ postinduction (PI). The enzymes AST, GGT, ALP and CK were determined, and seric total protein (TP), albumin, urea, creatinine, blood count, total plasmatic protein (TPP), fibrinogen (PF), glucose and L-lactate were quantified. Clinical manifestations of lactic acidosis and lower ruminal $\mathrm{pH}$ values were observed $8 \mathrm{~h}$ PI, with (P $<0.05)$ in SG compared to the basal moment. Neutrophils showed higher scores $(\mathrm{P}<0.05)$ in $\mathrm{CG}$ compared to $\mathrm{SG} 4 \mathrm{~h}$ $\mathrm{PI}$. The PF reached significant values $(\mathrm{P}<0.05)$ in $\mathrm{CG} 48 \mathrm{~h}$ PI compared to SG. Urea decreased $(\mathrm{P}<0.05)$ in both groups $12 \mathrm{~h}$ PI. Glucose increased $(\mathrm{P}<0.05)$ when compared to $\mathrm{CG}$ at basal moment. There was a decrease $(\mathrm{P}<0.05)$ at urinary $\mathrm{pH} 12 \mathrm{~h}$ up to $48 \mathrm{~h} \mathrm{PI}$, compared to $0 \mathrm{~h}$ time in $\mathrm{CG}$, while the SG decreased $(\mathrm{P}<0.05)$ just at moments $12 \mathrm{~h}$ and $16 \mathrm{~h}$ PI. Salinomycin did not prevent acidosis, however, favored the reestablishment of the animals that received it.

KEYWORDS: clinical biochemistry; fermentation disturbance; ionophores; small ruminants. 


\section{INTRODUÇÃO}

A acidose láctica ruminal aguda é uma doença metabólica, caracterizada por distúrbio fermentativo que acontece após a ingestão súbita e/ou não adaptada de carboidratos facilmente digeríveis, desencadeando modificações na flora microbiana que comprometem a dinâmica ruminal, frequentemente com reflexo sistêmico de acidose e vários processos secundários que são potencialmente prejudiciais à produção animal (HUNGATE et al., 1952; DUNLOP, 1972; BRAUN et al., 1992; ORTOLANI, 1995; OWENS et al., 1998).

Os sinais clínicos variam conforme a severidade da doença. $\mathrm{O}$ apetite e os movimentos ruminais estão reduzidos ou ausentes, observa-se diarréia, desidratação e distensão do abdômen além de taquicardia e taquipneia, um quadro de laminite também pode ser observado, ressaltando que nos casos superagudos, os animais permanecem em decúbito, podendo ir a óbito devido à severa insuficiência circulatória (HUBER, 1971; CAKALA et al., 1974; DOUGHERTY et al., 1975; MARUTA \& ORTOLANI, 2002; MIRANDA NETO et al., 2005).

A observação dos sinais clínicos, análise do fluído ruminal e urina, quando associados ao conhecimento das alterações sanguíneas permitem melhor avaliação do quadro clínico e direcionamento apropriado da terapêutica (PATRA et al., 1993; NIKOLOV, 2003; CÂMARA, 2008). No entanto, devido aos prejuízos que acarreta, o mais racional é evitar que a enfermidade aconteça (VIEIRA et al., 2006).

Algumas medidas preventivas da acidose láctica são empregadas em ruminantes como o fornecimento gradativo de carboidratos na alimentação, a utilização de tamponantes e de alguns grupos de antibióticos na dieta. Dentre as práticas que vêm demonstrando resultados satisfatórios, destaca-se a utilização de ionóforos como a monensina e a lasalocida, gerando boas perspectivas para o controle desse distúrbio fermentativo, por inibirem o crescimento das bactérias Gram-positivas, Streptococcus bovis e Lactobacillus $\mathrm{sp}$, as maiores produtoras de ácido láctico no rúmen (BEEDE \& FARLIN, 1977; KEZAR \& CHURCH, 1979b; MUIR et al., 1980b; BERGEN \& BATES, 1984; AFONSO et al., 2000).

Vale salientar que outro composto dessa categoria, a salinomicina, está sendo investigado com propriedade no controle de alguns transtornos digestivos em ruminantes (NAGARAJA et al., 1985; USAGAWA, 1992); contudo, são escassas as informações referentes ao seu uso na espécie ovina como preventivo da acidose láctica ruminal.

Diante do exposto, objetivou-se descrever o perfil hematológico e bioquímico de ovinos suplementados com salinomicina submetidos à acidose láctica ruminal.

\section{MATERIAL E MÉTODOS}

O trabalho foi realizado no aprisco de experimentação animal da Clínica de Bovinos da Universidade Federal Rural de Pernambuco com 12 ovinos adultos, entre machos e fêmeas, mestiços da raça Santa Inês, pesando em média $30 \mathrm{Kg}$ e clinicamente sadios. Foi implantada cânula ruminal permanente em cada animal, conforme DEHGHANI \& GHADRDANI (1995). O período de recuperação cirúrgica e adaptação ao manejo alimentar foi de quatro semanas, anteriores à indução da acidose ruminal. Nesse intervalo e durante a fase de indução da acidose, os animais receberam farelo de soja (150g) duas vezes ao dia, às 8:00h e 16:00h, além dos capins elefante (Pennisetum purpureum) e tifton (Cynodon dactylon), sal mineral e água ad libitum.

Os ovinos foram subdivididos em dois grupos de seis animais, sendo um grupo controle (GC) e o outro que recebeu a Salinomicina (Salocin 120 Intervet.) (GS), administrada diretamente no rúmen, através da fístula, na dose diária de $30 \mathrm{mg} / \mathrm{kg}$ da dieta, por animal, no decorrer de 42 dias e durante a fase de indução (MERCHEN e BERGER, 1985).

Os valores fisiológicos (0h) para as variáveis estudadas foram estabelecidos durante os dois dias anteriores à indução por avaliação clínica por meio do exame físico e laboratorial, hemograma, da bioquímica sérica e $\mathrm{pH}$ ruminal e urinário, conforme recomendações de JAIN (1993) e RADOSTITS et al. (2007). No exame clínico dos animais, observaram-se as características de atitude, comportamento, apetite, coloração das mucosas, frequência cardíaca e respiratória, motilidade retículoruminal (frequência e amplitude), temperatura retal e o aspecto das fezes.

Após o período inicial de adaptação, a aplicação do antibiótico foi mantida e a acidose induzida nos ovinos fornecendo como substrato $10 \mathrm{~g}$ de sacarose $/ \mathrm{kg}$ de peso corpóreo, através da fístula ruminal, às oito horas da manhã, antes da alimentação matinal (DELAK \& ADAMIC, 1959).

As observações clínicas no decorrer do experimento e a colheita das amostras de fluído ruminal, sangue e urina foram realizadas em intervalos de 4h, 8h, 12h, 16h, 24h, 32h e 48h pós-indução (PI), a fim de observar o surgimento de prováveis alterações clínicas e laboratoriais indicativas de acidose láctica, 
conforme recomendações de KEZAR \& $\mathrm{CHURCH}$ (1979a).

O fluído ruminal foi obtido por sonda, acoplada à bomba de sucção, introduzida através da cânula e a determinação do $\mathrm{pH}$ foi realizada em medidor de $\mathrm{pH}$ digital (pHmetro: Corning 30) (DIRKSEN, 1993). Para as análises hematológicas, obtiveram-se três amostras de sangue em tubos com vácuo mediante punção da veia jugular, sendo um tubo com EDTA à $10 \%$ para o hemograma, um tubo com fluoreto de sódio para determinação da glicose e lactato plasmáticos, e um tubo siliconizado para obtenção do soro para determinação da proteína total sérica (PT), albumina, ureia, creatinina, aspartato aminotransferase (AST), gama glutamiltransferase (GGT), fosfatase alcalina (FA) e creatina quinase (CK). $\mathrm{O}$ pH urinário foi analisado conforme recomendações de ORTOLANI (2002).

Os valores obtidos foram analisados estatisticamente ao longo de oito momentos experimentais, comparando cada momento experimental com o momento inicial $(0 \mathrm{~h})$ dentro do grupo, e entre os grupos controle e salinomicina. As variáveis foram submetidas à análise de variância, empregando-se as estatísticas $\mathrm{F}$, sendo consideradas significativas quando $\mathrm{p}<0,05$, realizando-se o contraste entre as médias pelo método Turkey e calculando-se a diferença mínima significativa (dms) para alfa igual a 0,05 . Para as variáveis $\mathrm{pH}$ ruminal, eosinófilos, basófilos, fibrinogênio plasmático (FP), aspartato aminotransferase (AST) e gama glutamiltransferase (GGT), obteve-se a mediana como medida de tendência central, com a prova de Friedman para amostras dependentes e método de Mann Whitney na comparação entre os grupos, usando o $\chi^{2}$ e calculando a dms para alfa igual a 0,05 (CURI, 1997).

\section{RESULTADOS}

A indução da acidose nos ovinos provocou um quadro clínico brando de acidose ruminal, caracterizado por taquicardia discreta, inapetência, apatia e consequente anorexia. Na maioria dos animais, em ambos os grupos, houve redução da motilidade do rúmen (frequência e amplitude), durante o período de acidose ruminal $(8 \mathrm{~h}$ à $16 \mathrm{~h} \mathrm{PI})$, e excreção fezes pastosas. Foi observada variação na hidratação de alguns animais, com exsicose mais intensa no GC quando comparado ao GS, não havendo importância clínica frente às demais alterações. Tais achados foram evidentes desde $8 \mathrm{~h}$ PI, retornando à normalidade a partir de 32h PI.

$\mathrm{O} \mathrm{pH}$ ruminal apresentou queda progressiva dos valores iniciais, alcançando os níveis mais baixos 8h PI, com 6.06 no GC e 6.07 no GS, havendo diferença estatística significativa $(\mathrm{P}<0,05)$ no grupo que recebeu o ionóforo quando comparado ao momento inicial. Mesmo assim, a recuperação dos valores normais (Figura 1), aconteceu de forma mais expressiva nos animais do GS quando comparado aos animais do GC, mas sem diferença estatística $(\mathrm{P}>0,05)$.

No eritrograma, as hemácias, hematócrito e hemoglobina assumiram os maiores valores (Tabela 1) entre $12 \mathrm{~h}$ e $16 \mathrm{~h}$ PI no GC, enquanto no GS essas variáveis tiveram incremento posteriormente, entre $16 \mathrm{~h}$ e 32PI. O volume corpuscular médio (VCM) e a concentração de hemoglobina corpuscular média (CHCM) variaram pouco em relação aos índices primários. Não foi observada diferença significativa $(\mathrm{P}>0,05)$ para as variáveis descritas, entre os grupos nem ao longo dos momentos de observação dentro de cada grupo.

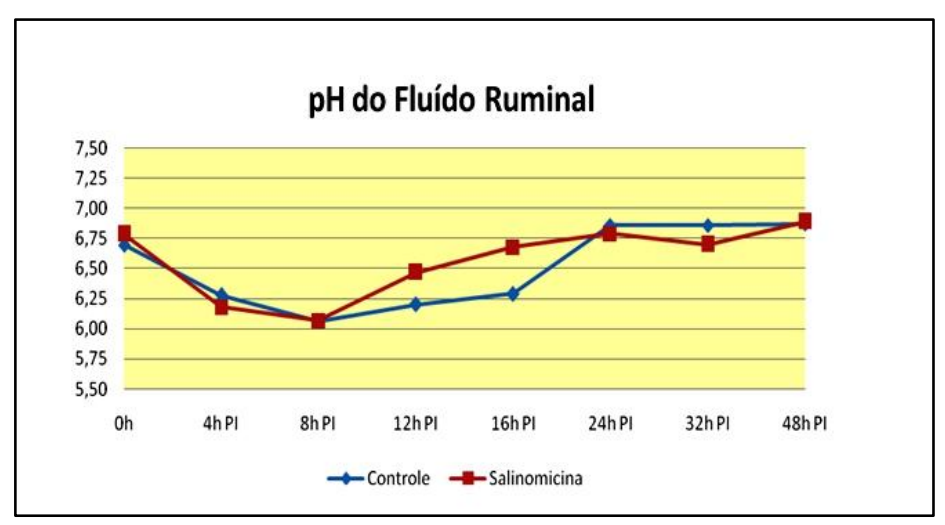

FIGURA1. Valores de mediana do $\mathrm{pH}$ ruminal dos ovinos nos GC e GS, com acidose láctica ruminal experimental, nos momentos basal (0h) e após a indução com sacarose $(10 \mathrm{~g} / \mathrm{Kg}$ de peso corpóreo) 
TABELA 1. Perfil hematológico e bioquímico de ovinos dos grupos controle (GC) e salinomicina (GS) nos momentos basal (0h) e após a indução da acidose ruminal com sacarose $(10 \mathrm{~g} / \mathrm{Kg}$ de peso corpóreo)

\begin{tabular}{lcccccccc}
\hline \multirow{2}{*}{ Variável } & \multicolumn{7}{c}{ Grupo Controle (GC) Horas Pós Indução } \\
\cline { 2 - 9 } & 0 & 4 & 8 & 12 & 16 & 24 & 32 & 48 \\
\cline { 2 - 9 } Hemácias (x10//LL) & $12,71 \pm 1,49$ & $13,00 \pm 1,93$ & $12,74 \pm 1,92$ & $13,88 \pm 2,40$ & $13,53 \pm 1,99$ & $12,99 \pm 2,32$ & $13,48 \pm 1,93$ & $12,60 \pm 1,69$ \\
Hematócrito (\%) & $33,21 \pm 3,09$ & $33,14 \pm 4,53$ & $33,57 \pm 4,20$ & $36,14 \pm 4,53$ & $35,29 \pm 4,31$ & $34,14 \pm 4,45$ & $35,29 \pm 4,03$ & $34,57 \pm 3,91$ \\
Hemoglobina (g/dL) & $11,21 \pm 1,11$ & $11,37 \pm 1,50$ & $11,21 \pm 1,46$ & $11,94 \pm 1,46$ & $12,21 \pm 1,42$ & $11,35 \pm 1,16$ & $11,83 \pm 1,53$ & $11,64 \pm 1,20$ \\
PPT (g/dL) & $7,60 \pm 0,31$ & $7,34 \pm 0,32$ & $7,43 \pm 0,37$ & $7,73 \pm 0,36$ & $7,80 \pm 0,35$ & $7,66 \pm 0,22$ & $7,76 \pm 0,37$ & $7,66 \pm 0,30$ \\
PT (g/dL) & $8,30 \pm 0,38$ & $7,71 \pm 0,52$ & $7,84 \pm 0,81$ & $8,27 \pm 0,64$ & $8,16 \pm 0,56$ & $7,94 \pm 0,57$ & $7,99 \pm 0,39$ & $7,92 \pm 0,69$ \\
Albumina (g/dL) & $2,58 \pm 0,18$ & $2,53 \pm 0,26$ & $2,61 \pm 0,24$ & $2,66 \pm 0,34$ & $2,67 \pm 0,27$ & $2,59 \pm 0,27$ & $2,64 \pm 0,26$ & $2,62 \pm 0,26$ \\
Creatinina (mg/dL) & $0,67 \pm 0,09$ & $0,65 \pm 0,11$ & $0,63 \pm 0,07$ & $0,68 \pm 0,12$ & $0,68 \pm 0,11$ & $0,66 \pm 0,12$ & $0,74 \pm 0,17$ & $0,69 \pm 0,16$ \\
AST (U/L) & 96,90 & 96,93 & 99,53 & 102,16 & 104,78 & 107,39 & 104,74 & 94,29 \\
GGT (U/L) & 49,73 & 45,90 & 45,90 & 53,55 & 53,55 & 49,73 & 49,73 & 45,90
\end{tabular}

FA (U/L) $\quad 132,67 \pm 51,38 \quad 129,91 \pm 57,37 \quad 124,38 \pm 49,18 \quad 123,00 \pm 55,60 \quad 117,46 \pm 50,13 \quad 127,14 \pm 47,38 \quad 116,10 \pm 41,63 \quad 109,18 \pm 42,09$

$\mathrm{CK}(\mathrm{U} / \mathrm{L}) \quad 186,20 \pm 46,52 \quad 161,90 \pm 25,10 \quad 165,95 \pm 32,30 \quad 178,10 \pm 36,58 \quad 174,05 \pm 28,41 \quad 165,95 \pm 18,29 \quad 174,05 \pm 28,41 \quad 186,20 \pm 33,20$

\begin{tabular}{|c|c|c|c|c|c|c|c|c|}
\hline & \multicolumn{8}{|c|}{ Grupo Salinomicina (GS) Horas Pós Indução } \\
\hline & 0 & 4 & 8 & 12 & 16 & 24 & 32 & 48 \\
\hline Hemácias $\left(x 10^{6} / \mu \mathrm{L}\right)$ & $12,28 \pm 1,14$ & $12,23 \pm 2,86$ & $12,32 \pm 2,00$ & $12,52 \pm 2,02$ & $12,52 \pm 2,11$ & $12,67 \pm 2,48$ & $13,59 \pm 3,27$ & $12,13 \pm 3,10$ \\
\hline Hematócrito (\%) & $30,43 \pm 2,96$ & $31,71 \pm 4,50$ & $32,14 \pm 6,15$ & $31,71 \pm 4,54$ & $33,29 \pm 6,78$ & $33,14 \pm 9,03$ & $33,86 \pm 8,75$ & $31,43 \pm 8,08$ \\
\hline Hemoglobina (g/dL) & $10,48 \pm 0,95$ & $10,83 \pm 1,28$ & $10,50 \pm 1,79$ & $10,61 \pm 1,22$ & $10,67 \pm 1,35$ & $10,71 \pm 2,21$ & $11,06 \pm 2,47$ & $10,43 \pm 2,12$ \\
\hline PPT (g/dL) & $7,36 \pm 0,44$ & $7,44 \pm 0,71$ & $7,43 \pm 0,62$ & $7,53 \pm 0,63$ & $7,57 \pm 0,81$ & $7,56 \pm 1,07$ & $7,61 \pm 0,77$ & $7,33 \pm 0,77$ \\
\hline $\mathrm{PT}(\mathrm{g} / \mathrm{dL})$ & $7,74 \pm 0,87$ & $7,81 \pm 0,91$ & $7,66 \pm 0,65$ & $7,67 \pm 0,85$ & $7,88 \pm 0,70$ & $7,66 \pm 0,47$ & $7,67 \pm 0,44$ & $7,46 \pm 0,73$ \\
\hline Albumina (g/dL) & $2,57 \pm 0,30$ & $2,55 \pm 0,46$ & $2,58 \pm 0,29$ & $2,67 \pm 0,33$ & $2,67 \pm 0,32$ & $2,62 \pm 0,29$ & $2,62 \pm 0,34$ & $2,48 \pm 0,27$ \\
\hline Creatinina $(\mathrm{mg} / \mathrm{dL})$ & $0,76 \pm 0,14$ & $0,77 \pm 0,22$ & $0,79 \pm 0,27$ & $0,80 \pm 0,25$ & $0,83 \pm 0,25$ & $0,81 \pm 0,29$ & $0,83 \pm 0,30$ & $0,76 \pm 0,25$ \\
\hline AST (U/L) & 85,12 & 83,81 & 78,57 & 94,29 & 91,67 & 91,67 & 91,67 & 81,19 \\
\hline GGT (U/L) & 49,73 & 53,55 & 53,55 & 57,38 & 53,55 & 57,38 & 53,55 & 53,55 \\
\hline $\mathrm{FA}(\mathrm{U} / \mathrm{L})$ & $149,25 \pm 53,93$ & $161,70 \pm 78,26$ & $157,52 \pm 65,06$ & $153,39 \pm 63,32$ & $157,54 \pm 68,16$ & $156,16 \pm 71,01$ & $158,94 \pm 78,55$ & $163,07 \pm 72,78$ \\
\hline $\mathrm{CK}(\mathrm{U} / \mathrm{L})$ & $176,07 \pm 58,88$ & $226,66 \pm 135,36$ & $202,37 \pm 101,50$ & $190,22 \pm 83,30$ & $190,22 \pm 91,40$ & $174,04 \pm 77,44$ & $174,03 \pm 60,30$ & $149,74 \pm 62,23$ \\
\hline
\end{tabular}

A resposta inflamatória, observada na contagem leucocitária, foi discreta e assumiu padrão semelhante nos dois grupos experimentais a partir de 8h PI. Tanto no GC como no GS, os valores mais elevados foram observados nos momentos $12 \mathrm{~h}$ PI e $16 \mathrm{~h}$ PI, não existindo em ambos os grupos e entre eles diferenças significativas $(\mathrm{P}>0,05)$. Para o GS, a contagem de leucócitos diminuiu gradativamente; no entanto, os valores permaneceram ligeiramente acima dos limites iniciais. Os neutrófilos segmentados foram as principais células de defesa responsáveis por esse padrão de distribuição (Figura 2), havendo diferença significativa $(\mathrm{P}<0,05)$ no momento $4 \mathrm{~h}$ PI do GC $(4774,29 / \mu \mathrm{L})$ quando comparado ao GS (3430/ $\mu \mathrm{L})$.

Os valores da proteína plasmática total (PPT) evoluíram de forma progressiva, alcançando índices mais elevados nos momentos $16 \mathrm{~h}$ PI $(7,8 \mathrm{~g} / \mathrm{dL} \pm 0,35)$ e $32 \mathrm{~h}$ PI $(7,61 \mathrm{~g} / \mathrm{dL} \pm 0,77)$ para os GC e GS, respectivamente. Quando comparados aos índices iniciais e cada momento entre os grupos, não houve significado estatístico $(\mathrm{P}>0,05)$. No GC o fibrinogênio plasmático (FP) apresentou o valor de maior expressão às $48 \mathrm{~h}$ PI $(400 \mathrm{mg} / \mathrm{dL})$, com diferença estatística significativa $(\mathrm{P}<0,05)$ quando comparado ao GS $(200 \mathrm{mg} / \mathrm{dL})$. Nos animais do GS, os índices de FP não 
apresentaram variação na maioria dos momentos experimentais. Quando comparados os momentos após a indução com o momento $0 h$, não foi observada diferença estatística significativa $(\mathrm{P}>0,05)$ para ambos os grupos (Figura 3).

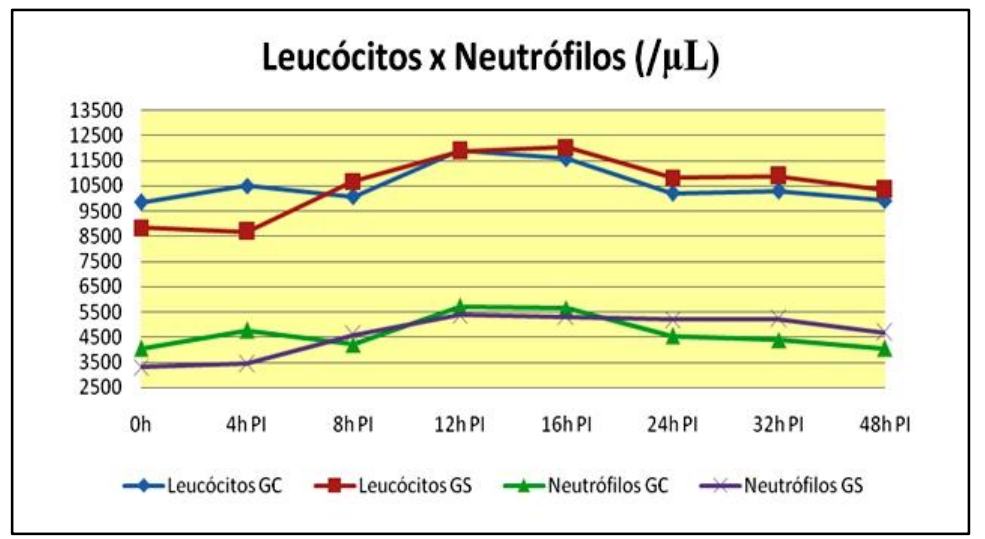

FIGURA 2. Valores médios da contagem de leucócitos e segmentados neutrófilos $(/ \mu \mathrm{L})$ dos ovinos nos GC e GS, com acidose láctica ruminal experimental, nos momentos basal (0h) e após a indução com sacarose $(10 \mathrm{~g} / \mathrm{Kg}$ de peso corpóreo).

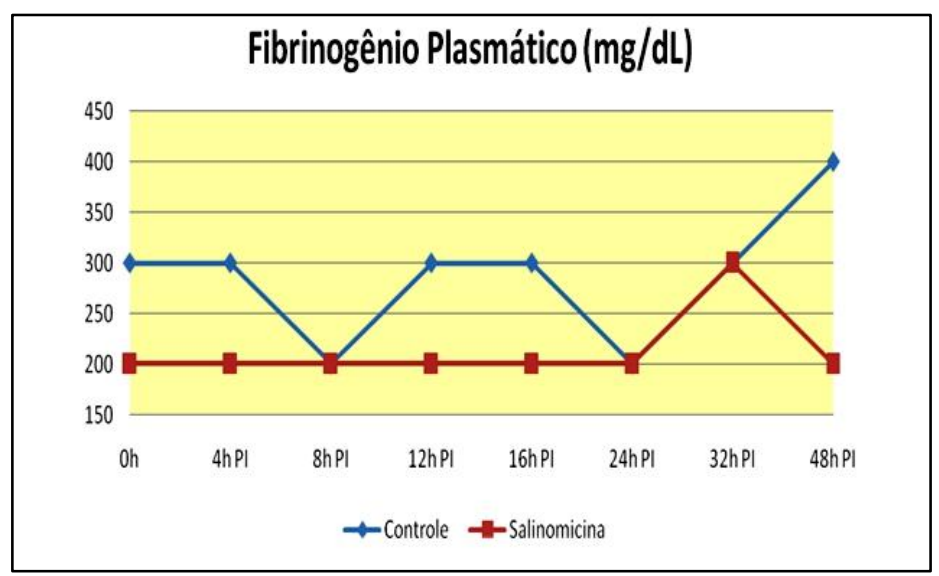

FIGURA 3. Valores de mediana da concentração de fibrinogênio plasmático (mg/dL) dos ovinos nos GC e GS, com acidose láctica ruminal experimental, nos momentos basal (0h) e após a indução com sacarose $(10 \mathrm{~g} / \mathrm{Kg}$ de peso corpóreo).

A proteína total sérica (PTS) não sofreu variações expressivas ao longo dos períodos de observação $(\mathrm{P}>0,05)$, retornando a limites ligeiramente inferiores ao final do experimento (Tabela 1). A fração representada pela albumina apresentou incremento $16 \mathrm{~h}$ PI para ambos os grupos, permanecendo ligeiramente acima do valor inicial para o GC e um pouco abaixo do momento 0h para o GS, porém sem expressão significativa neste comportamento $(\mathrm{P}>0,05)$.
Após a indução da acidose láctica, os índices para a uréia reduziram de maneira significativa $(\mathrm{P}<0,05)$ em relação ao momento inicial $(0 \mathrm{~h})$, de forma mais expressiva $12 \mathrm{~h}$ PI em ambos os grupos (Figura 4), alcançando valores de $45,03 \mathrm{mg} / \mathrm{dL}( \pm 12,68)$ e $54,38 \mathrm{mg} / \mathrm{dL}( \pm 11,69)$ para os GC e GS, respectivamente. Quando os grupos foram comparados, não houve diferença estatística significativa $(\mathrm{P}>0,05)$. 


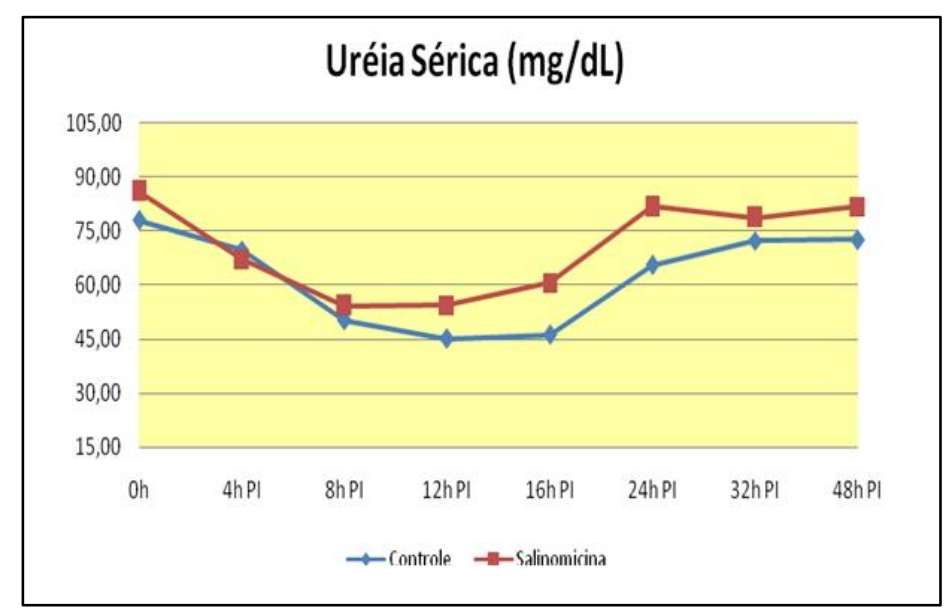

FIGURA 4. Valores médios da uréia sérica $(\mathrm{mg} / \mathrm{dL})$ dos ovinos nos GC e GS, com acidose láctica ruminal experimental, nos momentos basal (0h) e após a indução com sacarose (10g/Kg de peso corpóreo).

A creatinina apresentou comportamento homogêneo (Tabela 1), permanecendo com distribuição praticamente linear em ambos os grupos, com os maiores valores observados 32h PI, porém não houve diferença estatística significativa $(\mathrm{P}>0,05)$ entre os momentos experimentais e o momento inicial. Quando os GC e GS foram comparados, não foi observada diferença estatística significativa $(\mathrm{P}>0,05)$.

Quanto às enzimas AST, GGT e FA não houve variação significativa $(\mathrm{P}>0,05)$ nos valores ao longo do período experimental (Tabela 1), quando comparado ao momento basal e entre os GC e GS.
Após a indução da acidose ruminal, foi verificada elevação nos valores da glicose plasmática, em ambos os grupos, que foi significativa $(\mathrm{P}<0,05)$ no GC 4h PI $(76,95 \mathrm{mg} / \mathrm{dL})$, quando comparada ao momento inicial $(59,63 \mathrm{mg} / \mathrm{dL})$. No GS, apesar do incremento, o valor médio mais alto $(88,05 \mathrm{mg} / \mathrm{dL})$ foi observado $16 \mathrm{~h}$ PI, porém sem revelar significado estatístico $(\mathrm{P}>0,05)$. Ao analisar o comportamento dessa variável entre os grupos, não foi observada diferença significativa $(\mathrm{P}>0,05)$ entre eles ao longo dos momentos experimentais (Figura 5).

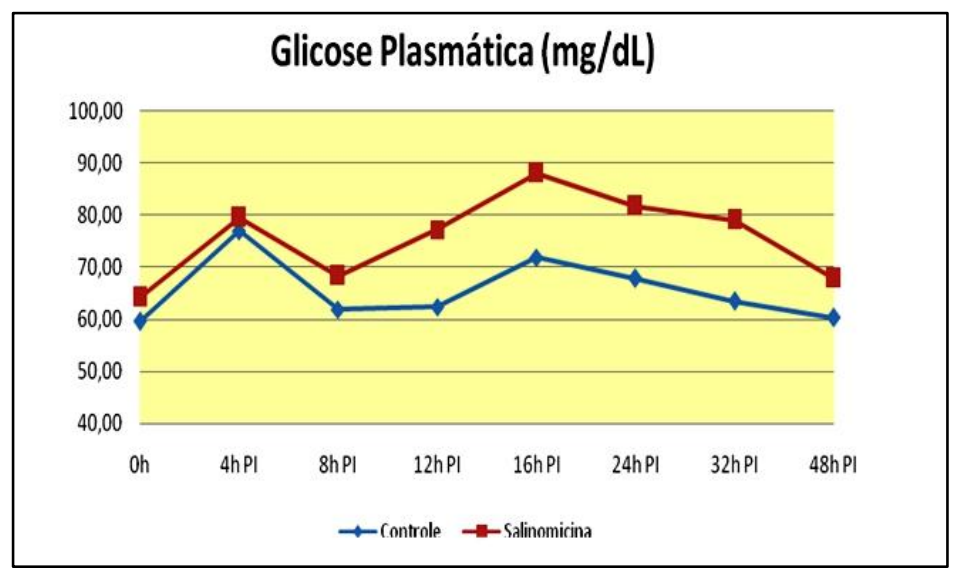

FIGURA 5. Valores médios da glicose plasmática $(\mathrm{mg} / \mathrm{dL})$ dos ovinos nos $\mathrm{GC}$ e GS, com acidose láctica ruminal experimental, nos momentos basal (0h) e após a indução com sacarose $(10 \mathrm{~g} / \mathrm{Kg}$ de peso corpóreo)

Foi constatada elevação nos valores do LLactato, com os maiores índices médios observados 4h PI, alcançando $16,50 \mathrm{mg} / \mathrm{dL}$ no GC e $30,72 \mathrm{mg} / \mathrm{dL}$ nos animais do GS, não sendo constatado significado estatístico $(\mathrm{P}>0,05)$ ao confrontar com os achados do momento inicial. Na comparação dos grupos, não foi observada diferença significativa $(\mathrm{P}>0,05)$, em que os animais do GC retornaram aos índices iniciais e o GS demonstrou valores ligeiramente inferiores (Figura 6). 


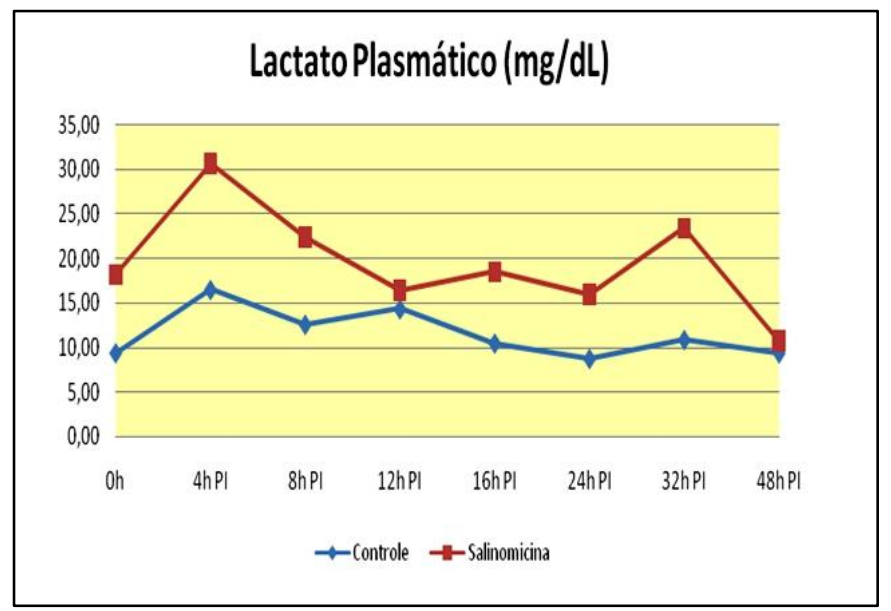

FIGURA 6. Valores médios do lactato plasmático $(\mathrm{mg} / \mathrm{dL})$ dos ovinos nos GC e GS, com acidose láctica ruminal experimental, nos momentos basal (0h) e após a indução com sacarose (10g/Kg de peso corpóreo).

Houve queda significativa $(\mathrm{P}<0,05)$ nos valores médios do $\mathrm{pH}$ urinário (Figura 7) após a indução da acidose ruminal, desde o momento $12 \mathrm{~h}$ PI $(6,43)$ e nos momentos seguintes, até o último momento experimental $(5,5)$ em relação ao momento Oh $(7,86)$ no GC. Para o GS apenas os momentos 12h $(5,5)$ e $16 \mathrm{~h}$ PI $(5,64)$ apresentaram diminuição significativa $(\mathrm{P}<0,05)$ do $\mathrm{pH}$ em relação ao momento inicial $(8,18)$. Na comparação entre os grupos, houve diferença significativa $(\mathrm{P}<0,05)$ com menor valor médio no GS $(5,5)$ em relação ao $\mathrm{GC}(6,43)$ no momento $12 \mathrm{~h}$ PI. No entanto, ao final do experimento (48h PI), o $\mathrm{pH}$ do GC permaneceu baixo $(5,5)$, com diferença significativa $(\mathrm{P}<0,05)$, em relação aos valores médios do GS $(7,6)$. Ao longo dos momentos experimentais, o grupo salinomicina estabilizou o $\mathrm{pH}$, retornando à limites semelhantes aos basais.

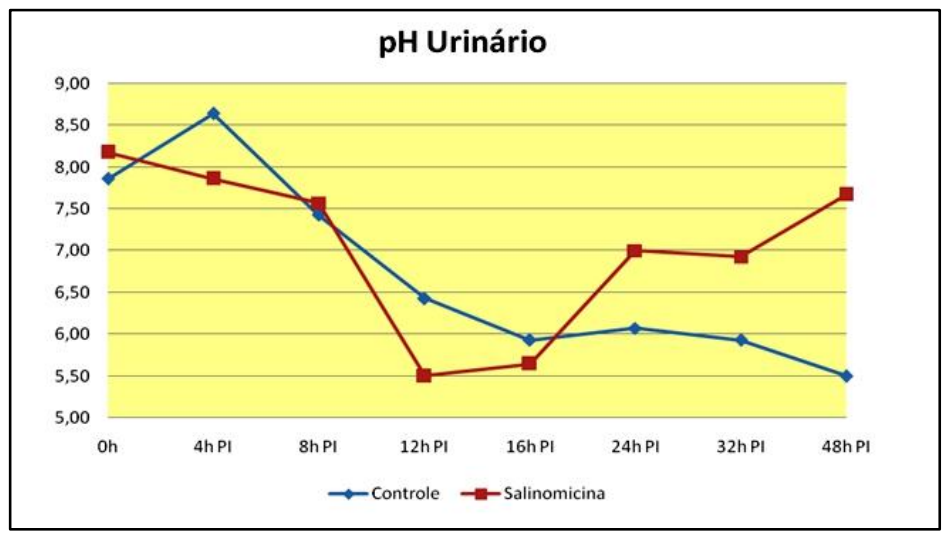

FIGURA 7. Valores médios do pH urinário dos ovinos nos GC e GS, com acidose láctica ruminal experimental, nos momentos basal (0h) e após a indução com sacarose (10g/Kg de peso corpóreo).

\section{DISCUSSÃO}

Os sinais clínicos observados nos ovinos após a indução da acidose são semelhantes àqueles relatados por autores que provocaram e/ou descreveram o transtorno digestivo com o uso de diversos substratos, tanto em pequenos como em grandes ruminantes. Entretanto, no presente estudo, o quadro clínico apresentado pelos animais foi mais brando quando comparado a outros relatos, nos quais 
os animais apresentaram estase ruminal, diarréia, desidratação intensa, alterações neurológicas e até óbito nos casos mais intensos (CAKALA et al., 1974; CAO et al., 1987; BRAUN et al., 1992; NAGARAJA \& LECHTENBERG, 2007; COMMUN et al., 2009; MIRANDA NETO et al., 2011). Tais diferenças, provavelmente, ocorreram pela menor quantidade e tipo de substrato utilizado para induzir a acidose nos animais deste estudo. Esses achados diferem de ensaios com a monensina, nos quais o ionóforo se mostrou efetivo em prevenir a acidose em ruminantes, provavelmente por um mecanismo mais eficaz em otimizar o status energético e favorecer a microbiota produtora de ácido propiônico em detrimento daquelas que produzem ácido láctico, quando comparado ao uso da salinomicina (NAGARAJA et al., 1985; MOUSSA, 1994; AFONSO et al., 2002b).

A diminuição nos valores do $\mathrm{pH}$ ruminal coincidiu com o descrito na literatura, mas de forma menos intensa, retornando a limites próximos daqueles observados nos momentos iniciais, e de forma mais pronunciada nos animais do GS, demonstrando o aspecto favorável da utilização desse ionóforo. Essa alteração é justificada nos casos de acidose láctica, quando o $\mathrm{pH}$ cai a níveis críticos logo nas primeiras 4-8 horas após a ingestão do substrato que desencadeou o distúrbio, estando tanto mais baixo quanto maior for a produção inicial de ácidos graxos voláteis (AGVs) pelas bactérias Gram negativas e continuada de ácido láctico pelas bactérias Gram positivas que passam a predominar graças ao baixo pH (NOCEK, 1997; OWENS et al., 1998). Esses achados refletem o tipo e quantidade do substrato utilizado na indução da acidose, bem como a interação da salinomicina com a população microbiana, demostrando menor poder de controle do distúrbio fermentativo quando comparado a estudos com outros antibióticos seletivos como a monensina, a capreomicina e a lailomicina, nos quais é atribuído ao ionóforo um bom controle do $\mathrm{pH}$ em distúrbios fermentativos, tornando o restabelecimento dos animais enfermos aparentemente mais rápido (MUIR et al., 1980a; MUIR et al., 1980b; AHUJA et al., 1990; BAUER et al., 1995; MBANZAMIHIGO et al., 1995; AFONSO et al., 2002a).

No eritrograma, embora não tenha havido diferença estatística entre os grupos para as variáveis analisadas, notou-se que os animais do GC apresentaram maior elevação dos seus valores. Esse comportamento provavelmente ocorreu em virtude da maior intensidade do distúrbio fermentativo sofrido pelos animais controle, o que se reflete no grau de desidratação observado. Nos animais do GS, os achados refletem o melhor desempenho, quando comparado ao $\mathrm{GC}$, frente às alterações patológicas do equilíbrio osmótico e o estresse acarretado pela acidose experimental, visto que, em casos de acidose láctica, o efluxo de líquidos dos compartimentos intra e extracelular para o rúmen no intuito de manter o equilíbrio intra ruminal resulta no incremento do hematócrito (TELLE \& PRISTON, 1971). Por outro lado, o estresse gerado com o quadro de acidose provoca contração esplênica devido à ação da epinefrina podendo haver hemoconcentração decorrente da quantidade de hemácias lançadas na corrente sanguínea periférica e consequente aumento do hematócrito (JAIN, 1993). No entanto, esse último caso é incomum em ruminantes e não é acompanhado por aumento paralelo nos valores da proteína plasmática como foi observado neste trabalho.

Comportamento semelhante para o hematócrito foi observado por PATRA et al. (1997) ao induzirem acidose ruminal em ovinos, mas de forma mais intensa. $\mathrm{O}$ maior incremento da $\mathrm{Hb}$ no GC reflete provavelmente a desidratação ocorrida e demonstrada pelo maior valor de hematócrito após a indução nesses animais quando comparado aos animais do GS, que manteve o volume plasmático mais estável em relação ao controle. Existem relatos de incremento nos índices da hemoglobina em ruminantes com indigestão aguda, atribuído à diminuição do volume plasmático bem como à contração esplênica. No entanto, HUBER (1971), ao induzir acidose em ovelhas, observou que a diminuição no volume plasmático foi mais expressiva que a elevação do hematócrito indicando que o último subestima o grau de desidratação plasmática. Os índices observados para a PPT são considerados normais para a espécie, com os valores mais altos relacionados à intensidade da desidratação ocorrida nos animais em cada grupo (ANGELOV et al., 1996; ALMEIDA et al., 2008).

Os achados do leucograma se assemelham, em menor intensidade, aos relatados por CAO et al. (1987), UNDERWOOD (1992), MOHAMED NOUR et al. (1998) e NIKOLOV (2000), em caprinos, bovinos e bubalinos com acidose, nos quais descrevem que a mobilização de neutrófilos está relacionada à inflamação na mucosa do rúmen provocada pela concentração elevada de ácido láctico no fluído ruminal que, sendo irritante ao epitélio, desencadeia todo o processo de ruminite. A recuperação do quadro leucocitário, nos momentos seguintes, se deu em função da melhoria da condição clínica dos animais, uma vez que a evolução da acidose láctica induzida, mesmo aguda, foi branda como verificada por GOZHO et al. (2007) e DANSCHER et al. (2010) em vacas com acidose ruminal subaguda. 
O aumento na proteína de fase aguda, fibrinogênio plasmático (FP), foi mais intenso nos animais do GC do que naqueles do GS, embora ambos os grupos tenham permanecido dentro do limite considerado normal para a espécie ovina (GARRY, 2002). Esse achado nos animais do GS indica um melhor controle dos aspectos adversos provocados pela acidose, como a lise de bactérias Gram negativas, e que estão diretamente relacionados com o incremento da resposta inflamatória como sugerem ECKERSALL (2000), GOZHO et al. (2007), BRAUN et al. (2010) e DANSCHER et al. (2010). No presente estudo, o estímulo inflamatório foi discreto, não havendo resposta expressiva como a descrita pelos autores, provavelmente pelo tipo e menor quantidade de substrato utilizado, também pela possível ação da salinomicina evitando lise de bactérias, visto que nos animais tratados com o ionóforo praticamente não houve aumento nas concentrações de fibrinogênio quando comparado aos animais do GC.

Os resultados obtidos para a PT foram semelhantes aos relatados por VIHAN et al. (1982) e METKARI et al. (2001), que não observaram alterações para essa variável em animais acometidos do distúrbio, que é justificado pela menor intensidade do processo ocorrido nos animais analisados neste estudo. Diferentemente do descrito por ALMEIDA et al. (2008), que explicam esse achado principalmente pela hemoconcentração em decorrência da desidratação durante a enfermidade. Achados semelhantes para a albumina foram descritos por VIHAN et al. (1982) em caprinos com acidose, e por AUSTIN \& WILDE (1985) em ovelhas prenhes com acidose induzida, suplementadas ou não com o ionóforo monensina, nos quais não houve alterações marcantes dessa proteína.

O padrão de diminuição nos valores da uréia e posterior retorno a índices semelhantes aos iniciais neste trabalho corroboram com os achados de ALMEIDA et al. (2008) na acidose em caprinos. Esse achado é consequência, provavelmente, da modificação no padrão fermentativo intraruminal por diminuição da população microbiana produtora de $\mathrm{NH}_{3}$, refletindo em queda na ureia sérica durante os momentos mais críticos de acidose ruminal (MOUSSA, 1994; BRAUN et al., 2010). Os dados deste trabalho diferem dos obtidos por PATRA et al. (1996) e METKARI et al. (2001), em ovinos e caprinos, com a enfermidade também induzida, cujos animais apresentaram distribuição inversa, com os maiores valores nos períodos mais críticos de acidose. A distribuição da ureia neste estudo demonstra a menor severidade do quadro clínico de acidose dos animais quando comparada à maior severidade da acidose e desidratação descritas nos experimentos citados.

Os índices da creatinina se mantiveram dentro do limite considerado normal para a espécie, de forma semelhante aos relatos de ALMEIDA (2008) em caprinos com acidose láctica ruminal experimental. Os achados descritos discordam daqueles observados por NAGARAJA et al. (1985) em bovinos, ao comparar a eficiência da salinomicina em relação aos ionóforos lasalocida e monensina na prevenção da acidose, e dos observados por BROWN et al. (1999), estudando ovelhas com o mesmo distúrbio, pois ambos obtiveram valores maiores para a creatinina em período semelhante ao descrito neste trabalho, o que pode ser justificado pela menor perfusão sanguínea renal provocada pela maior intensidade do distúrbio fermentativo naqueles trabalhos, como explicam GONZÁLEZ \& SCHEFFER (2002).

A elevação dos teores da AST foi discreta durante o acompanhamento dos sinais de acidose em ambos os grupos experimentais, demonstrando não haver comprometimento aparente da função hepática, nem danos teciduais, pois os animais em estudo apresentaram um quadro brando de acidose, não ficaram prostrados nem permaneceram muito tempo em decúbito ao ponto de provocar incremento nas concentrações da AST (BROWN et al., 1999; ALMEIDA et al., 2008). Achados discordantes foram relatados por BRAUN et al. (1992), DAS \& MISRA (1992) e PATRA et al. (1996), que evidenciaram aumentos marcantes nessa enzima a partir de $24 \mathrm{~h}$ após a indução da doença, associando esse achado aos danos hepáticos e musculares. Essas diferenças estão relacionadas, provavelmente, ao tipo de substrato que foi empregado, a sacarose, bem como à quantidade administrada, que foi bem menor no presente estudo.

A enzima GGT não foi comprometida nos animais durante a indução da acidose, visto que apesar das oscilações observadas, as mesmas não foram indicativas de dano hepático, pois permaneceram no limite da normalidade para a espécie ovina (KANEKO et al., 2008). Divergências foram observadas nos resultados de BRAUN et al. (1992) e PATRA et al. (1996) em caprinos e ovinos com acidose, que observaram que os valores para essa enzima foram elevados, sendo atribuído os achados à lesão hepatobiliar.

Os valores obtidos para a FA mantiveram-se dentro da faixa considerada normal para a espécie (KANEKO et al., 2008). Achados semelhantes foram relatados por ALMEIDA et al. (2008), em casos de acidose láctica induzida em caprinos, e por NAGARAJA et al. (1985), empregando a salinomicina em bovinos como modelo de 
prevenção.

Resultados semelhantes para a CK foram descritos por ALMEIDA et al. (2008), na acidose em caprinos, nos quais não foram observadas alterações dessa variável. Entretanto, nos relatos de LAL et al. (1991), BRAUN et al. (1992) e UNDERWOOD (1992), obtidos nos casos de acidose láctica em caprinos, houve elevações expressivas para a CK, que foram justificadas pelos danos musculares provocados devido ao maior tempo em decúbito dos animais. A indução da acidose nos animais do presente estudo proporcionou um quadro brando de acidose láctica, no qual os animais apesar do apetite diminuído, atonia ruminal em alguns deles, agrupamentos de fezes, dentre outros, não chegaram a ficar prostrados nem em decúbito por muito tempo, não havendo estímulo suficiente para acarretar o incremento nos valores dessa enzima que é um marcador sensível de comprometimento muscular (GARRY, 2002).

Elevações nos valores da glicose, empregando-se diferentes tipos de substratos e gerando manifestações clínicas de intensidades variadas, em ruminantes com acidose láctica, foram relatadas por ANGELOV et al. (1995), PATRA et al. (1997), MOHAMED NOUR et al. (1998) e ALMEIDA et al. (2008), que justificam a hiperglicemia temporária graças à maior reabsorção de glicose, a partir do excedente que não foi metabolizado pela microbiota ruminal, como também devido ao aumento na síntese de glicose pelo fígado, oriunda da maior produção e absorção de ácidos graxos voláteis no rúmen (NAGARAJA et al., 1985). Apesar de não ter existido diferença entre os grupos experimentais, os ovinos que receberam a salinomicina apresentaram valores mais elevados de glicose, durante o período da acidose ruminal, justificados pela ação seletiva do ionóforo em favorecer o crescimento de bactérias que sintetizam propionato, principal precursor gliconeogênico (AUSTIN \& WILDE, 1985; NAGARAJA et al., 1985; MOUSSA, 1994).

Diante dos resultados para o L-Lactato plasmático, pôde ser constatado que houve um quadro brando de lacticemia nos animais em estudo nos dois grupos, em decorrência de sua absorção para a corrente sanguínea devido à elevação desse ácido no fluído ruminal, o que implicou nas manifestações clínicas assinaladas. Essa alteração é bem característica no processo de acidose láctica e surge em consequência do desequilíbrio entre a sua síntese e utilização por parte da flora bacteriana produtora e consumidora, pois o mesmo no rúmen é apenas um produto intermediário da fermentação bacteriana Gram positiva (ANGELOV et al., 1996; NOCEK, 1997; MOHAMED NOUR et al., 1998).
Os achados obtidos são semelhantes aos relatados por BAUER et al. (1995), que, ao empregarem a laidlomicina em bovinos, com o intuito de minimizar a ocorrência da acidose subaguda experimental, observaram que o mesmo não se mostrou tão eficaz. Entretanto, esses achados diferem dos relatados de AHUJA et al. (1990) e NAGARAJA et al. (1985), que, empregando esse e outros tipos de ionóforos em bovinos e búfalos, observaram resultado favorável em animais com acidose induzida, nos quais os compostos foram eficazes no controle da enfermidade, reduzindo o teor de ácido láctico no rúmen e consequentemente o sanguíneo.

Os achados deste trabalho demonstram o aspecto favorável do uso da salinomicina em animais expostos a situações que possam desencadear a acidose láctica ruminal e, consequentemente, acidose metabólica, visto que os animais tratados com o ionóforo retornaram à valores normais de $\mathrm{pH}$ urinário de forma mais rápida e consistente que os animais do GC que continuaram a apresentar valores baixos de $\mathrm{pH}$ urinário indicando maior dificuldade dos mesmos em metabolizar o excesso de AGVs e outros produtos de fermentação como o ácido láctico acumulados, estando no limite da normalidade se considerarmos o súbito aporte de carboidratos. Essa queda nos valores do $\mathrm{pH}$ urinário é atribuída principalmente à excreção do íon $\mathrm{H}+$, que está atrelada à eliminação de amônia, bem como de moléculas de fosfato e lactato, sendo um indicador precoce e mais confiável em casos brandos de acidose ruminal porque os rins secretam íons $\mathrm{H}+$ antes que o mecanismo de reabsorção de ácido láctico seja superado (UNDERWOOD, 1992; PATRA et al., 1993; ORTOLANI, 2002). Por outro lado, BROWN et al. (1999), em estudo com ovelhas adultas, verificaram que $\mathrm{o} \mathrm{pH}$ urinário não sofreu influência na acidose induzida, havendo discordância em relação aos achados do presente estudo que demonstram diminuição expressiva no $\mathrm{pH}$ urinário dos animais acometidos por acidose láctica experimental, mas que não receberam tratamento ou medida preventiva como a utilização da salinomicina. Esses autores ponderam que variações individuais podem interferir no valor do $\mathrm{pH}$, tornando seu uso limitado como indicador de acidose.

\section{CONCLUSÕES}

Diante dos objetivos propostos, pode-se concluir que a indução da acidose provocou manifestações clínicas características da doença, em sua forma branda, em ambos os grupos experimentais. Em função da evolução clínica de 
pouca intensidade, as alterações hematológicas e bioquímicas se apresentaram com pouca expressão. $O$ emprego da salinomicina não preveniu o surgimento do distúrbio fermentativo; entretanto, nos animais que a utilizaram, foi verificado que a recuperação clínica dos parâmetros hematológicos e bioquímicos foi mais precoce.

\section{REFERÊNCIAS}

AFONSO, J. A. B.; MENDONÇA, C. L.; FIORAVANTE, M. C. S.; KUCHEMBUCK, M. R. G. Características e indicações clínicas dos ionóforos para ruminantes. Revista do Conselho Federal de Medicina Veterinária, v. 6, n. 20, p. 29-36, 2000.

AFONSO, J. A. B.; KUCHEMBUCK, M. R. G.; FELTRIN, L. P. Z.; LAPOSY, C. B.; KOHAYAGAWA, A.; MENDONÇA, C. L.; TAKAHIRA, R. K. Efeito da monensina sódica sobre as características do suco rumenal na acidose láctica experimental em ovinos. Revista Brasileira de Medicina Veterinária, v. 24, n.5, p. 203210, 2002a.

AFONSO, J. A. B.; CIARLINI, P. C.; KUCHEMBUCK, M. R. G.; KOHAYAGAWA, A.; FELTRIN, L. P. Z.; CIARLINI, D. R. P.; LAPOSY, C. B.; MENDONÇA, C. L.; TAKAHIRA, R. K. Metabolismo oxidativo dos neutrófilos de ovinos tratados com monensina sódica e experimentalmente submetidos à acidose ruminal. Pesquisa Veterinária Brasileira, v.22, n.4, p. 129-134, 2002b.

AHUJA, A. K.; RANDHAWA, S. S.; RATHOR, S. S. Effect of monensin in ameliorating subacute lactic acidosis in buffalo calves. Acta Veterinaria Brno, v. 59, p. 171-178, 1990.

ALMEIDA, M. Z. P. R. B.; MENDONÇA, C. L.; AFONSO, J. A. B.; MIRANDA NETO, E. G. Estudo clínico, hematológico e bioquímico em caprinos submetidos à acidose láctica ruminal induzida experimentalmente. Veterinária e Zootecnia, v. 15, n. 1, p. 100-113, 2008.

ANGELOV, G.; NIKOLOV, Y; ANGELOV, A.Changes in acid-base variables and some biochemical parameters in caprine acute rumen acidosis. Veterinarski Arhiv, v. 65, n. 2 , p. $43-48,1995$.

ANGELOV, G.; NIKOLOV, Y; ANGELOV, A. Changes in acid-base parameters, blood sugar and blood lactate in experimental acute rumen acidosis in sheep. Indian Veterinary Journal, v. 73, p. 309-314, 1996.

AUSTIN, A. R.; WILDE, R. M. The effect of sodium monensin on pregnant ewes. British Veterinary Journal, v. 141, n. 6 , p. $628-634,1985$.

BAUER, M. L.; HEROLD, D. W.; BRITTON, R. A.; STOCK, R. A.; KLOPFENSTEIN, T. J.; YATES, D. A. Efficacy of laidlomycin proprionate to reduce ruminal acidosis in cattle. Journal of Animal Science, London, v.
73, p. 3445-3454, 1995.

BEEDE, D. K.; FARLIN, S. D. Effects of capreomycin disulfate and oxamycin on ruminal $\mathrm{pH}$, lactate and volatile fatty acid concentrations in sheep experiencing induced acidosis. Journal of Animal Science, v. 45, n. 2, p. 393401, 1977.

BERGEN, W. J.; BATES, D. B. Ionophores: Their effect on production efficiency and mode of action. Journal of Animal Science, v. 58, p. 1465-1483, 1984.

BRAUN, U.; RIHS, T.; SCHEFER, U. Ruminal lactic acidosis in sheep and goats. Veterinary Record, v. 130, p. 343-349, 1992.

BRAUN, J. P.; TRUMEL, C.; BÉZILlE, P. Clinical biochemistry in sheep: A selected review. Small Ruminant Research, v. 92, p. 10-18, 2010.

BROWN, M. S.; HALFORD, D. M.; GALYEAN, M. L.; KREHBIEL, C. R.; DUFF, G. Effect of ruminal glucose infusion on dry matter intake, urinary nitrogen composition, and serum metabolite and hormone profile in ewes. Journal of Animal Science, v. 77, p. 3068-3076, 1999.

CAKALA, S.; BORKOWSKI, T.; ALBRYCHT, A. Rumen acidosis in sheep induced with different doses of saccharose. Polskie Archiwun Weterynaryjne, v.17, p. 117-130, 1974.

CÂMARA, A. Efeito da salinomicina na prevenção da acidose láctica ruminal experimental em ovinos. Mossoró: UFERSA, 2008, 76p. Dissertação (Mestrado em Ciência Animal) - Programa de Pós-Graduação em Ciência Animal, Universidade Federal Rural do SemiÁrido, Mossoró, 2008. http://www2.ufersa.edu.br/portal/view/uploads/setores/80/ Disserta\%C3\%A7\%C3\%A3o_Adaucides\%C2\%A0C\%C3 $\%$ A2mera.pdf

CAO, G. R.; ENGLISH, P. B.; FILIPPICH, L. J.; ONGLIS, S. Experimentally induced lactic acidosis in the goat. Australian Veterinary Journal, v. 64, n.12, p. 367370, 1987.

COMMUN, L.; MIALON, M. M.; MARTIN, C.; BAUMONT, R.; VEISSIER, I. Risk of subacute ruminal acidosis in sheep with separate access to forage and concentrate. Journal of Animal Science, v 87, p. 33723379, 2009.

CURI, P.R. Metodologia e análise da pesquisa em ciências biológicas. Botucatu: Tipomic, 1997. 263 p.

DANSCHER, A. M.; THOEFNER, M. B.; HEEGAARD, P. M. H.; EKSTR ØM, C. T.; JACOBSEN, S. Acute phase protein response during acute ruminal acidosis in cattle. Science, 2010. Doi:10.1016/j.livsci2010.06.009.

DAS, S. K.; MISRA, S. K. Liver function in experimental acidosis in goat. Indian Journal of Animal Sciences, v. 62, n. 3, p. 243-244, 1992.

DEHGHANI, S. N.; GHADRDANI, A. M. Bovine rumenotomy: Comparision of four surgical techniques. 
Canadian Veterinary Journal, v. 36, n.11, 693-697 1995.

DELAK, M., ADAMIC, S. Contribution to the knowledge of saccharose intoxication in sheep. Veterinary Archives, v. 29, p. 214-222, 1959.

DIRKSEN, G. Sistema digestivo. In: DIRKSEN, G, GRÜNDER, H. D., STÖBER, M. Rosenberger exame clínico dos bovinos. 3 ed., Rio de Janeiro: Guanabara Koogan, 1993. p. 166-228.

DOUGHERTY, R. W.; RILEY, J. L.; COOK, H. M. Changes in motility and $\mathrm{pH}$ in the digestive tract of experimentally overfed sheep. American Journal of Veterinary Research, v. 36, n. 6, p. 827-829, 1975.

DUNLOP, R. H. Pathogenesis of ruminant lactic acidosis. Advances in Veterinary Science and Comparative Medicine, v. 16, p.259-302, 1972.

ECKERSALL, P. D. Recent advances and future prospects for the use of acute phase proteins as markers of disease in animal. Revue de Médecine Vétérinaire, v. 151, n. 7, p. 577-584, 2000.

GARRY, F. B. Diseases of the alimentary tract, p. 722747. In: SMITH, B. P. (Ed.). Large Animal Internal Medicine. $3^{\text {rd }}$ ed. Mosby: St. Louis, 2002.

GONZÁLEZ, F. H. D.; SCHEFFER, J. S. F. Perfil sanguíneo: Ferramenta de análise clínica, metabólica e nutricional. In: GONZÁLEZ, F. H. D et al. Avaliação metabólico-nutricional de vacas leiteiras por meio de fluídos corporais (sangue, leite e urina). Arquivos do $\mathbf{2 9}^{\circ}$ Congresso Nacional de Medicina Veterinária, Gramado, RS, $\quad$ p. $\quad 5-17,2002$. http://www6.ufrgs.br/favet/lacvet/restrito/pdf/avalia_ao\% 20metabolica\%20vacas.pdf\#page $=5$

GOZHO, G. N.; KRAUSE, D. O.; PLAIZIER, J. C. Ruminal lipopolysaccharide concentration and inflammatory response during grain-induced subacute acidosis in dairy cows. Journal of Dairy Science, v. 90, n. 2, p. 856-866, 2007.

HUBER, T. L. Effect of acute indigestion on compartmental water volumes and osmolality in sheep. American Journal of Veterinary Research, v. 32, n. 6, p. 887-890, 1971.

HUNGATE, R. E.; DOUGHERTY, R. H.; BRYANT, M. P.; CELLO, R. M. Microbiological and physiological changes associated with acute indigestion in sheep. Cornell Veterinarian, v. 42, p. 423-449, 1952.

JAIN, N. C. Essentials of veterinary hematology. 5. ed., Philadelphia: Lea \& Febiger, 1993. 417p.

KANEKO, J. J.; HARVEY, J. W.; BRUSS, M. L. Clinical biochemistry of domestic animals. 6.ed. New York: Academic Press, 2008. 916p.

KEZAR, W.W., CHURCH, D.C. Ruminal changes during the onset and recovery of induced lactic acidosis in sheep. Journal of Animal Science, v.49, n. 5, p. 1161-1167, 1979a.
KEZAR, W.W., CHURCH, D.C. Effect of thiopeptin and sodium bicarbonate on the prevention of lactic acidosis induced in sheep. Journal of Animal Science, v.49, n. 5, p. 1396-1402, 1979b.

LAL, S. B. et al. Biochemical alterations in serum and cerebr-spinal fluid in experimental acidosis in goats. Research in Veterinary Science, v. 50, p. 208-210, 1991.

MARUTA, C. A.; ORTOLANI, E. L. Susceptibilidade de bovinos das raças jersey e gir à acidose láctica ruminal: I Variáveis ruminais e fecais. Ciência Rural, v. 32, n. 1, p. 55-59, 2002a.

MBANZAMIHIGO, L.; VAN NEVEL, C. J.; DEMEYER, D. I. Adaptation of rúmen fermentation to monensin. Reproduction Nutritional Development, v. 35, n. 4, p. 353-365, 1995.

MERCHEN, N. R.; BERGER, L. L. Effect of salinomycin level on nutrient digestibility and ruminal characteristics of sheep and feedlot performance of cattle. Journal of Animal Science, v. 60, n. 5, p. 1338-1346, 1985.

METKARI, S. M. et al. Management of experimentally induced lactic acidosis in goats. Indian Veterinary Journal, v. 78, p.692-694, 2001.

MIRANDA NETO, E. G.; AFONSO, J. A. B.; MENDONÇA, C. L.; ALMEIDA, M. Z. P. R. B. Estudo clínico e características do suco ruminal de caprinos com acidose láctica induzida experimentalmente. Pesquisa Veterinária Brasileira, v. 25, n. 2, p. 73-78, 2005.

MIRANDA NETO, E. G.; AFONSO, J. A. B.; SILVA, S. T. G.; MENDONÇA, C. L. Aspectos clínicos e a bioquímica ruminal de caprinos submetidos à acidose experimental e suplementados ou não com monensina sódica. Pesquisa Veterinária Brasileira, v. 31, n. 5, p. 416-424, 2011.

MOHAMED NOUR, M. S.; ABUSAMRA, M. T.; HAGO, B. E. D. Experimental induced acidosis in Nubian goats: Clinical, biochemical and pathological investigations. Small Ruminant Research, v. 31, p. 7-17, 1998.

MOUSSA, H. M. Ruminal and blood characteristics of nubian goats dosed with the growth promoter monensin. Acta Veterinaria Brno, v. 63, p. 13-17, 1994.

MUIR, L. A.; RICKES, E. L.; DUQUETTE, P. F.; SMITH, G. E. Control of wheat induced lactic acidosis in sheep by thiopeptin and related antibiotics. Journal of Animal Science, v.50, n. 3, p. 547-553, 1980a.

MUIR, L. A.; DUQUETTE, P. F.; RICKES, E. L.; SMITH, G. E. Thiopeptin for the prevention of ovine lactic acidosis induced by diet change. Journal of Animal Science, v.51, n. 5, p. 1182-1188, 1980b.

NAGARAJA, T. G.; AVERY, T. B.; GALITZER, S. J.; HARMON, D. L. Effect of ionophore antibiotics on experimentally induced lactic acidosis in cattle. American Journal of Veterinary Research, v.46, p. 2444-52, 1985.

NAGARAJA, T. G.; LECHTENBERG, K. F. Acidosis in 
feedlot cattle. Veterinary Clinics of Food Animals, v. 23, p. 333-350, 2007.

NIKOLOV, Y. Some biochemical changes in cerebrospinal flui, blood and rumen fluid in experimental ruminal acidosis in buffalo calves. Indian Veterinary Journal, v. 77, p. 957-960, 2000

NIKOLOV, Y. Biochemical alterations in rumen liquor, blood, cerebrospinal fluid and urine in experimental acute ruminal lactic acidosis in sheep. Indian Veterinary Journal, v. 80, p. 36-39, Jan. 2003.

NOCEK, J. E. Bovine acidosis: Implications on laminitis. Journal of Dairy Science, v. 80, p. 1005-1028, 1997.

ORTOLANI, E. L. Induction of lactic acidosis in cattle with sucrose: relationship between dose, rumen fluid $\mathrm{pH}$ and animal size. Veterinary and Human Toxicology, v. 37, n. 5, p.462-64, 1995.

ORTOLANI, E. L. Diagnóstico de doenças nutricionais e metabólicas por meio de exame de urina em ruminantes. In: GONZÁLEZ, F. H. D.; ORTOLANI, E. L.; BARROS, L.; CAMPOS, R. Avaliação metabólico-nutricional de vacas leiteiras por meio de fluídos corporais (sangue, leite e urina). Arquivos do $2^{\circ}$ Congresso Nacional de Medicina Veterinária, Gramado, RS, p. 18-26, 2002. http://www6.ufrgs.br/favet/lacvet/restrito/pdf/avalia_ao\% 20 metabolica $\% 20$ vacas.pdf\#page $=5$

OWENS, F. N.; SECRIST, D. S.; HILL, W. J.; GILL, D. R. Acidosis in cattle: A review. Journal of the American Society of Animal Science, v. 76, p. 275-286, 1998.

PATRA, R. C.; LAL, S. B.; SWARUP, D. Physicochemical alterations in blood, cerebrospinal fluid and urine in experimental lactic acidosis in sheep. Research in Veterinary Science, v. 54, p. 217-220, 1993.
PATRA, R. C.; LAL, S. B.; SWARUP, D. Biochemical profile of rumen liquor, blood and urine in experimental acidosis in sheep. Small Ruminant Research, v. 19, n. 2, p. 177-180, 1996.

PATRA, R. C.; LAL, S. B.; SWARUP, D. Therapeutic management of experimental ruminal acidosis in sheep. Indian Veterinary Journal, v. 74, n. 3, p. 237-240, March 1997.

RADOSTITS, O. M.; HINCHCLIFF, K. W.; BLOOD, D. C.; GAY, C. C. Veterinary Medicine. A textbook of the diseases of cattle, horses, sheep, pigs and goats. $10^{\text {th }}$ ed. St Louis: Saunders, 2007. 2156p.

TELE, P. P.; PRESTON, R. L. Ovine lactic acidosis: Intraruminal and systemic. Journal of Animal Science, v. 33, n. 3, p. 699-705, 1971.

UNDERWOOD, W. J. Rumen lactic acidosis. Part II. Clinical signs, diagnosis, treatment and prevention. The Compendium - Food Animal, v. 14, n. 9, p. 1265-1269, 1992.

USAGAWA, T. Effects of monensin and salinomycin on the In Vitro foam stability of sheep rumen fluid. Animal Science and Technology, Japan, v. 63, p. 16-22, 1992.

VIEIRA, A. C. S. et al. Estudo retrospectivo da acidose láctica em caprinos e ovinos atendidos na Clínica de Bovinos, Campus Garanhuns/UFRPE. Revista Brasileira de Ciências Agrárias, v. 1, n. único, p. 97-101, 2006.

VIHAN, V. S.; WANI, G. M.; SAHNI, K. L. Observation on changes in blood serum in experimental rumen acidosis in goats. Indian Veterinary Journal, v. 59, p. 998-1000, 1982. 